ATIVIDADE EMPRESARIAL E BENS COMUNS: A APLICAÇÃO DO REGIME DE BENS COMUNS PARA DETERMINADOS BENS DA COMPANHIA

Tese de Doutorado

Orientador: Prof. Dr. José Marcelo Martins Proença

UNIVERSIDADE DE SÃO PAULO

FACULDADE DE DIREITO

São Paulo-SP

2019 


\section{ATIVIDADE EMPRESARIAL E BENS COMUNS: A APLICAÇÃO DO REGIME DE BENS COMUNS PARA DETERMINADOS BENS DA COMPANHIA}

Tese apresentada à Banca Examinadora do Programa de Pós-Graduação em Direito, da Faculdade de Direito da Universidade de São Paulo, como exigência parcial para a obtenção do título de Doutor em Direito, na área de concentração Direito Comercial, sob a orientação do Prof. Dr. José Marcelo Martins Proença.

UNIVERSIDADE DE SÃO PAULO

FACULDADE DE DIREITO

São Paulo-SP

2019 


\section{AGRADECIMENTOS}

A seção de agradecimentos nos permite um breve e sincero desprendimento do preciosismo técnico arraigado na elaboração de um trabalho acadêmico, proporcionando um momento dedicado àqueles que de forma direta ou indireta contribuíram para o resultado de anos de pesquisa e dedicação.

Partindo dessa breve consideração, esses agradecimentos devem ser iniciados com especial carinho e atenção ao meu orientador, Prof. Dr. José Marcelo Martins Proença, não apenas por todos os ensinamentos quando ainda me sentava às tábuas na graduação, mas também por todo o apoio durante a vida acadêmica, sendo para mim uma verdadeira inspiração para o exercício da docência. Para mim, o professor é acima de tudo um inspirador, algo que o Prof. José Marcelo sempre foi e continuará sendo para mim.

À Faculdade de Direito da Universidade de São Paulo só tenho a agradecer por todas as oportunidades. Após mais de uma década, não há como negar que já a considero a minha segunda casa. Aproveito para agradecer pelas críticas construtivas trazidas pelo Prof. Alessandro Octaviani e pela Prof ${ }^{a}$. Sheila Cerezetti durante a Banca de Qualificação, as quais muito contribuíram para o resultado deste ora apresentado.

Ao Ramunno Advogados, agradeço o constante apoio durante a elaboração desta tese. O escritório nasceu como um projeto de vida pessoal, sendo que pouco a pouco vislumbro que outros passaram a compartilhar desse mesmo sonho. Por trás de cada projeto, há, sobretudo, pessoas, sendo que são justamente essas pessoas que permitem a concretização dos mais importantes desafios. Meu muito obrigado à família RA (aos atuais e àqueles que contribuíram para todas as metas alcançadas): Giancarlo Bonizzio, João Marcelo Novaes Risi e Lucca Lukjanenko.

À Faculdade de Direito da Universidade Presbiteriana Mackenzie, em nome do Prof. Felipe Chiarello e meu amigo e líder do Núcleo de Direito Empresarial, Prof. Armando Luiz Rovai, e ao Insper, deixo o meu muito obrigado pela oportunidade de exercer continuamente a paixão pela docência.

Aos meus alunos, com destaque especial aos que integram o GEADS (Grupo de Estudos Avançados em Direito Societário), grupo do qual tenho a alegria 
de coordenar, agradeço por servirem como constante fonte de inspiração e motivação pelo aprimoramento contínuo exigido pela atividade docente. Grande parte do que fazemos tem como resultado algo direcionado a vocês, sendo que espero que este trabalho possa servir igualmente de inspiração e como forma de retribuição. Faço, aqui, especial menção aos alunos Adriano Sasseron, Larissa Vince e Mateus Assis, pelo auxílio na revisão final desta tese.

Aos meus amigos, agradeço por todo o apoio. Com o receio de cometer alguma injustiça, destaco aqueles que foram particularmente importantes nesta jornada, contribuindo com críticas, sugestões e reflexões com base nas páginas aqui escritas: André de Castro Moricochi, Daniel Tavela Luís, Gustavo Lacerda Franco, Mateus Garcia e Paco Manolo Camargo Alcalde.

À minha família, em especial aos meus pais - Fernando e Lúcia - e meu irmão - Franco -, agradeço por terem propiciado todas as oportunidades que tive, certamente decorrente do incessante incentivo aos estudos e por sempre acreditarem em mim.

À minha pessoa especial, Bárbara, meu agradecimento pela compreensão inserta em cada gesto carinhoso, cada sorriso e cada olhar.

Este trabalho representa o encerramento de um ciclo, cuja caminhada não teria sido a mesma sem a contribuição de vocês. 
Aos meus pais, Fernando e Lúcia.

Aos meus alunos. 
Some people say a man is made outta mud A poor man's made outta muscle and blood Muscle and blood and skin and bones

A mind that's a-weak and a back that's strong

You load sixteen tons, what do you get? Another day older and deeper in debt Saint Peter don't you call me 'cause I can't go I owe my soul to the company store

I was born one mornin' when the sun didn't shine I picked up my shovel and I walked to the mine

I loaded sixteen tons of number nine coal And the straw boss said "Well, a-bless my soul"

You load sixteen tons, what do you get? Another day older and deeper in debt Saint Peter don't you call me 'cause I can't go I owe my soul to the company store

I was born one mornin', it was drizzlin' rain

Fightin' and trouble are my middle name I was raised in the canebrake by an ol' mama lion Can't no-a high-toned woman make me walk the line

You load sixteen tons, what do you get? Another day older and deeper in debt Saint Peter don't you call me 'cause I can't go I owe my soul to the company store

If you see me comin', better step aside A lotta men didn't, a lotta men died One fist of iron, the other of steel If the right one don't a-get you, then the left one will

You load sixteen tons, what do you get? Another day older and deeper in debt Saint Peter don't you call me 'cause I can't go I owe my soul to the company store

(Letra de "Sixteen Tons" | Compositor: Merle Travis) 


\section{RESUMO}

Pedro Alves Lavacchini Ramunno. Atividade empresarial e bens comuns: a aplicação do regime de bens comuns para determinados bens da companhia. 2019. 206 páginas. Doutorado - Faculdade de Direito da Universidade de São Paulo, São Paulo, 21 de outubro 2019.

Este trabalho tem como objetivo analisar a possibilidade de caracterizar determinados bens da companhia como tendo natureza de bem comum, à luz das premissas metodológicas propostas pelo novo estruturalismo jurídico e partindo do conceito de bem comum desenvolvido por Elinor Ostrom. Diante do entendimento pela possibilidade dessa identificação em casos restritos, apresenta-se uma proposta de regulação para tais bens, que são referidos como "commons empresariais", o que demanda o enfrentamento das estruturas propriedade e empresa - enquanto atividade empresarial - de acordo com a premissa metodológica apresentada. A partir de uma lente inspirada nas reflexões de Direito e Economia, defende-se que a propriedade deve ser entendida como uma forma de internalização de externalidades e composta por feixes de direitos de propriedade (bundle of rights), ao passo que a atividade empresarial deve ser entendida como um instrumento para maximização de eficiência distributiva, em um posicionamento que se entende alinhado com os preceitos do institucionalismo organizativo, sendo que o preenchimento desse objetivo é identificado com o conceito de melhor interesse da companhia. Diante dessas considerações discutese a forma de internalização de titulares de interesses afetados pela destinação desses commons empresariais, o que deve ser feito sempre visando, justamente, ao melhor interesse da companhia. Nesse contexto defende-se que soluções autorregulatórias (voluntárias e compulsórias) seriam os instrumentos adequados para a promoção desse objetivo, sendo o contrato associativo plurilateral, visto como um método de organização de interesses, a forma jurídica adequada para tanto. 
Palavras-chave: bem comum; common empresarial; estruturalismo jurídico; interesse da companhia; eficiência distributiva; contrato associativo plurilateral 


\section{ABSTRACT}

Pedro Alves Lavacchini Ramunno. Business activity and commons: the application of the common's regime to company's goods. 2019. 206 pages. Doctorate- Faculty of Law, University of São Paulo, São Paulo, October $21^{\text {st }}$, 2019.

This thesis aims to analyze the possibility of characterizing certain company's assets as having nature of common-pool resource (CPR), due the light of methodological premises proposed by the so called "legal structuralism" and based on the concept of common-pool resource developed by Elinor Ostrom. Adopting the understanding that this identification is possible in a very specific set of scenarios, this thesis presents a proposal for regulation of said assets, here referred as "corporate commons". This proposal requires the confrontation of some core concepts, such as "property" and "company" - as a commercial activity - according to the abovementioned methodological premises. Through a Law \& Economics-inspired optics, it is defended that property should be understood as a method to internalize externalities, as well as a complex formed by a bundle of property rights, while business activity should be understood as an instrument for maximizing distributive efficiency, according to the precepts of organizational institutionalism, and the fulfillment of this goal is identified with a concept usually described by the term "company's best interest". Given these considerations, there is a debate on the most suitable way to internalize all parties whose interests may be affected by the destination of the corporate commons, which must be done aiming, precisely, the company's best interest. It is argued that self-regulatory solutions (both voluntary and compulsory) would be appropriate instruments to promote such internalization, especially by the means of a plurilateral associative agreement. 
Keywords: common-pool resource; corporate common; legal structuralism; company's interest; distributive efficiency; plurilateral associative contract 


\section{RÉSUMÉ}

\section{Pedro Alves Lavacchini Ramunno. Activité commercial et biens communs: l'application du régime des biens communs à certains biens de la société anonyme. 2019. 206 pages. Doctorat- Faculté de Droit, Université de São Paulo, São Paulo, 21 octobre 2019}

Cette thèse de doctorat ci vise à analyser la possibilité de caractériser certains biens de la société anonyme comme ayant un caractère de bien commun, à la lumière des prémisses méthodologiques proposées par le nouveau structuralisme juridique et du concept de bien commun développé par Elinor Ostrom. Face à la compréhension de la possibilité de cette identification dans certains cas limités, on proposé une réglementation à ces biens, appelés " commons commercials ", laquel demande la confrontation entre les structures de la propriété et de l'entreprise - en tant qu'activité commerciale - selon la prémisse méthodologique présentée. En partant d'une vision inspirée sur les réflexions de l'Analyse Économique du Droit, il est affirmé que la propriété devrait être entendu comme une forme d'internalisation d'externalités et composée d'un faisceau de droits («bundle of rights »), tandis que l'activité commerciale devrait être considérée comme un instrument de maximisation d'efficacité distributive, dans une position conforme aux principes de l'institutionnalisme organisationnel. L'accomplissement de cet objectif s'identifie comme le mieux des intérêts de la société anonyme. Face à ces considérations, la forme d'internalisation des détenteurs d'intérêts affectés par la destination de ces communs commercials est discutée, ce qui devrait toujours être fait dans le mieux des intérêts de la société anonyme. Dans ce contexte, il est affirmé que les solutions autorégulatrices (volontaires et obligatoires) seraient les instruments appropriés pour la promotion de cet objectif, étant le contrat associatif plurilatéral, vu comme une méthode d'organisation des intérêts, la forme juridique appropriée à cet effet. 
Mots-clés: bien commun; commun commercial; structuralisme juridique; intérêt de l'entreprise; efficacité distributive; contrat associatif plurilatéral 


\section{SUMÁRIO}

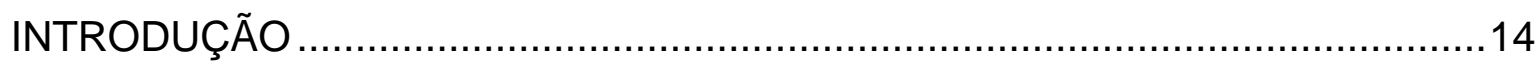

CAPÍTULO I - A PREMISSA METODOLÓGICA: O NOVO ESTRUTURALISMO

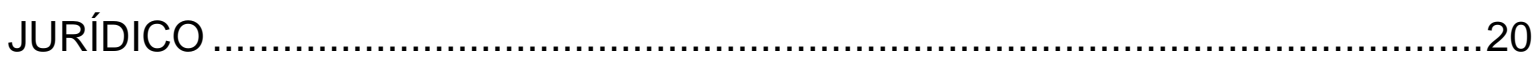

1.1. Plano deste Capítulo............................................................................20

1.2. Breves considerações sobre o estruturalismo: do conceito filosófico às correntes econômicas. O estruturalismo e a conformação das estruturas brasileiras

1.2.1. A evolução histórica da economia brasileira: o pano de fundo para as reflexões realizadas neste trabalho .25

1.3. As críticas ao estruturalismo e a ascensão do novo estruturalismo jurídico. A premissa metodológica deste trabalho.

1.4. Conclusão parcial 49

CAPÍTULO II - O CONCEITO DE BENS COMUNS E A POSSIBILIDADE DE CONSIDERAR CERTOS BENS DA COMPANHIA COMO BENS COMUNS

2.1. Plano deste Capítulo 52

2.2. A insuficiência da dicotomia entre bens públicos e bens privados: a ascensão dos bens comuns. Uma classificação de acordo com a natureza do bem.

2.3. Algumas experiências bem-sucedidas relacionadas a bens comuns .63

2.3.1. Sistemas de irrigação no Nepal 65

2.3.2. Terras comuns em Törbel, na Suíça. 66

2.3.3. Extrativismo de mangaba no Nordeste do Brasil

2.4. Verificação da possibilidade de considerar e aplicar o tratamento dado aos bens comuns a certos bens da companhia: os commons empresariais. .70

2.5. Conclusão parcial: enquadramento de determinados bens da companhia como bens comuns.

CAPÍTULO III - IMPLICAÇÕES JURÍDICAS DA APLICAÇÃO DA TEORIA DOS BENS COMUNS A CERTOS BENS DA COMPANHIA. 
3.2. Bens comuns e direito

3.2.1. A regulação dos bens comuns: a necessidade de uma intervenção estrutural. .90

3.2.1.1. As estruturas sob foco: a propriedade e a empresa. $O$ estruturalismo jurídico e suas implicações.

3.2.1.2. Além da dicotomia contratualismo-institucionalismo: uma questão de eficiência. O maior alinhamento à vertente do institucionalismo integracionista (ou organizativo)

3.3. Proposta: a regulação para os bens da companhia com natureza de bem comum

3.3.1. A estrutura a ser analisada: o controle empresarial.

3.3.2. Eficiência distributiva, função social do bem empresarial e o melhor interesse da companhia.

3.3.3. A função social da propriedade empresarial 136

3.4. Os feixes de direitos relacionados ao common empresarial. 148

3.5. Formas de alocação dos feixes de direitos relacionados ao common empresarial: autorregulação voluntária e autorregulação compulsória.

3.5.1. A autorregulação como forma para a alocação dos feixes de direitos relacionados ao common empresarial

3.5.2. O contrato associativo plurilateral como método para a internalização de externalidades.

3.6. Conclusão parcial: o contrato plurilateral associativo como instrumento para promover a cooperação e a maximização da eficiência distributiva 176

CONSIDERAÇÕES CONCLUSIVAS 179

REFERÊNCIAS BIBLIOGRÁFICAS. 186 


\section{INTRODUÇÃO}

Uma análise sob a ótica do novo estruturalismo jurídico ${ }^{1}$, que vise ao desenvolvimento, implica a revisitação crítica de certas estruturas determinantes para a concentração e a manutenção do poder, tais como a propriedade e a empresa. Quando o objeto de reflexão consiste na conjugação de ambas as estruturas, ou seja, no tratamento dos bens da empresa, em especial da companhia, igual pensamento crítico deve ser almejado.

Nesse sentido, a tese deste trabalho trata da possibilidade de aplicar o tratamento dado aos bens comuns a alguns bens da companhia, o que se propõe denominar "common empresarial", partindo do reconhecimento da insuficiência da tradicional dicotomia entre bens públicos e bens privados para esses bens, devido a suas características especiais, que possibilitariam considerá-los como detentores da natureza de bem comum. Para tanto, alguns questionamentos serão enfrentados para promover essa visão "às avessas"2 da propriedade e da empresa, muitos deles decorrentes da aplicação das considerações relacionadas ao Direito e à Economia ${ }^{3-4}$.

\footnotetext{
${ }^{1} \mathrm{O}$ termo estruturalismo jurídico se refere à crítica e transformação de estruturas (a exemplo do Estado, da propriedade e da empresa), formadas historicamente, que levam a relações de dominação e de concentração e manutenção de poder econômico, sem se preocuparem com os valores e interesses envolvidos. Sendo assim, a visão do estruturalismo jurídico pressupõe a necessidade de valoração dos interesses envolvidos, que está no cerne da organização jurídica das relações sociais, e afasta-se do funcionamento positivista do direito e da interpretação baseada no racionalismo jurídico, por favorecerem a manutenção das referidas estruturas de poder. Para uma análise aprofundada do estruturalismo jurídico v. SALOMÃO FILHO, Calixto. Novo estruturalismo jurídico: uma alternativa para o direito? In: Revista dos Tribunais, vol. 926. Dezembro, 2012, sendo de se destacar que as suas premissas serão endereçadas no decorrer do Capítulo I, que versará sobre a premissa metodológica adotada neste trabalho.

2 Faz-se aqui clara referência ao artigo de Fábio Konder Comparato, "O direito e o avesso" (COMPARATO, Fábio Konder. O direito e o avesso. In: Estudos Avançados. v. 23, n. 67. São Paulo, jan. 2009. pp. 6-22).

${ }^{3}$ Sobre a interface entre direito e economia e sua importância, cujas premissas estão alinhadas com o escopo proposto para este trabalho, destaca-se o seguinte excerto: "applying economics to the law shapes legal thought and language; in framing and detaling an order governed by law it necessarily frames the objective of law" (JOHNSTON, Jason S. Law, Economics and Post-Realist Explanation. Working Paper No. 137 - Post Realist. Yale Law School Program in Civil Liability, 1990. p. 5).

${ }^{4}$ Mais precisamente, além das premissas relativas a Law and Economics, as considerações realizadas neste trabalho estão alinhadas com as premissas propagadas pela área Direito, Economia e Organizações. Esta área teria por objetivo redefinir o modo pelo qual economistas e outros cientistas sociais pensam e investigam a Economia, as Organizações e as Instituições. Afasta-se, assim, do conceito da "firma" como mera função de produção e caminha para a firma como um modo de governança, o que dá às organizações papel antes ignorado. Nesse contexto, as reflexões de Oliver Williamson sobre o papel do ordenamento privado em contraste com o
} 
Em primeiro lugar, no Capítulo I deste trabalho, são realizadas algumas considerações acerca da premissa metodológica aqui sustentada, qual seja, o (novo) estruturalismo jurídico. Para tanto, inicia-se pela apresentação do conceito filosófico de estruturalismo, que serve como base para as diversas teses econômicas que têm por fundamento os ideais estruturalistas, com destaque para o estruturalismo cepalino (ou latino americano). Feita essa apresentação conceitual inicial, apresenta-se uma breve evolução histórica da economia brasileira, com o objetivo de delimitar o pano de fundo que serve como base para a atual composição das estruturas nacionais e para as reflexões feitas no decorrer deste trabalho.

A análise da evolução histórica das estruturas econômicas brasileiras, quando cotejadas com as premissas econômicas estruturalistas introduzem, por sua vez, as críticas apresentadas a esses modelos, o que culmina com a ascensão do chamado novo estruturalismo jurídico. Trata-se, justamente, da premissa metodológica na qual se sustentam os argumentos aqui defendidos. Destaca-se, desde logo, que, muito embora as premissas adotadas se sustentem sobretudo nas relevantes reflexões realizadas por Calixto Salomão Filho, as reflexões e conclusões atingidas neste trabalho podem dar a impressão (e de fato o fazem)

ordenamento público são de grande valia. Para o autor, o segundo é mais afeto ao estudo da Análise Econômica do Direito tradicional, enquanto a ênfase no ordenamento privado, ou seja, na capacidade das organizações funcionarem como instâncias para a solução de conflitos póscontratuais, tem papel central no enfoque do Direito, Economia e Organizações. Sobre o tema, v. ZYLBERSZTAJN, Decio; SZTAJN, Rachel. Análise Econômica do Direito e das Organizações. In: ZYLBERSZTAJN, Decio; SZTAJN, Rachel (Orgs.). Direito \& Economia: Análise Econômica do Direito e das Organizações. Rio de Janeiro: Elsevier, 2005. p. 13). Precisamente sobre a visão de Oliver Williamson, v. WILLIAMSON, O. E. Transaction Cost Economics Meets Posnerian Law and Economics. In: Journal of Institutional and Theoretical Economics. Vol. 149, No.1, 1993. pp. 73-87; bem como, WILLIAMSON, O. E. Por que Direito, Economia e Organizações? (trad. Decio Zylbersztajn). In: ZYLBERSZTAJN, Decio; SZTAJN, Rachel (Orgs.). Direito \& Economia: Análise Econômica do Direito e das Organizações. Rio de Janeiro: Elsevier, 2005. pp. 16-59. Cumpre ainda destacar a contribuição de Douglass North para o debate envolvendo Economia, Direito e Organizações, ao reconhecer que as organizações são arquitetadas de modo a buscar eficiência e que sua arquitetura é pautada pelo ambiente institucional, cf. NORTH, Douglass C. Economic Performance Through Time. In: The American Economic Review. Vol. 84, No. 3, jun./1994. pp. 359368. Por fim, com o intuito de sintetizar o âmbito de estudo de Direito, Economia e Organizações, destaca-se o excerto de Hirsch: "A new institucional perspective that relates to law, economics, and organization theory focuses on how feasible legal forms of organization work. It is based on the premise that legal institutions matter and lend themselves to analysis. The law, economics, and organization perspective rely on a firm-as-governance structure in which contracts are assumed to be incomplete and the action is concentrated on the mechanisms of ex post governance. It is positive and thoroughly interactive and makes use of transaction cost economics. Transaction cost economics considers transactions as the based unit of analysis and focuses on aligning them with alternative modes of governance, e.g., markets and departments, with the objective of economizing transaction costs." (HIRSCH, Werner Z. Law and Economics: An Introductory Analysis. $3^{\text {rd }}$ Ed. San Diego: Academic Press, 1999. p.11). 
que ao se referir, aqui, ao estruturalismo jurídico, adota-se um conceito ligeiramente mais alargado, o que em nenhuma hipótese afasta a precisão e profundidade dos argumentos do nobre professor.

Feita a apresentação da premissa metodológica adotada, no Capítulo II deste trabalho, baseando-se no estudo desenvolvido pela cientista política Elinor Ostrom $^{5}$, traça-se uma conceituação dos bens comuns, tendo por pressuposto a insuficiência da clássica dicotomia entre bens públicos e bens privados e o conceito adotado por Ostrom ao se referir aos common-pool resources (CPR) ou, simplementes commons ou bens comuns. Esta análise enfrenta brevemente os estudos de caso trazidos por Elinor Ostrom, bem como outras experiências nacionais e internacionais não apresentadas pela autora. Dessa reflexão delimitase o conceito de bem comum adotado nesta tese.

Importante salientar que o conceito bem comum, apesar de, em um primeiro momento, denotar que se leva em consideração critérios econômicos relacionados especialmente às características físicas desse bem, em realidade tem como fundamento a necessidade de acesso (econômico, social ou jurídico) de múltiplos interesses em relação a tal bem, independentemente de seus atributos físicos. Essa concepção de bem comum, como se procurará demonstrar, independente da titularidade jurídica do bem, ou seja, de quem é titular do direito de propriedade, reconhecido pelo ordenamento jurídico brasileiro (o próprio Estado, particulares, ou mesmo bem sem proprietário, que se aproximariam do tradicional conceito de res nullius).

Essa consideração implica desde logo afirmar que ao se caracterizar um bem como comum, faz-se referência à natureza do bem. Essa classificação não se confunde, por sua vez, ao tratamento que será proposto para a destinação que lhe será dada, tampouco podendo ser tratado como equivalente ao regime jurídico reconhecido pelo ordenamento para tal bem, que costuma classificá-los entre bens públicos e bens privados, principalmente.

\footnotetext{
${ }^{5}$ Elinor Ostrom foi a primeira mulher a receber o Prêmio Nobel de Economia, em 2009. Além disso, Ostrom possui graduação (1954), mestrado (1962) e doutorado (1965) pela Universidade da Califórnia, bem como foi professora da Universidade de Indiana e fundadora da Associação Internacional para Estudo da Propriedade Comum, que desde 2006 não conta mais com o termo "propriedade" em seu nome, International Association for the Study of Commons (IASC). Atualmente, a IASC é tida como uma das principais instituições responsáveis pela a propagação de reflexões e estudos relacionados aos bens comuns (commons). Não à toa, as reflexões da IASC são referidas em algumas passagens deste trabalho.
} 
Nesse contexto, partindo da análise de casos empiricamente bem-sucedidos relacionados à identificação de determinados bens como comuns, verifica-se a possibilidade de considerar e aplicar um tratamento especial a determinados bens da companhia, mormente integrantes do estabelecimento comercial. Isso envolve analisar a existência de identidade entre os elementos característicos dos comuns em alguns bens da companhia, quais sejam: o alto grau de subtrabilidade de uso $\mathrm{e}$ o alto grau de dificuldade de exclusão de terceiro em relação a esse bem, de acordo com as características apresentadas no decorrer desse segundo Capítulo.

Destaca-se que a delimitação do escopo de análise em torno dos bens da companhia não é arbitrária. Como se procurará demonstrar no decorrer deste trabalho, a discussão sobre a destinação de um bem de uma sociedade empresária é, em suma, uma discussão sobre interesses. Nesse contexto, a sociedade anônima, pelo seu caráter institucional e pelas razões de sua concepção no direito nacional, é o tipo societário propício para promover a organização e a internalização de interesses. Esse recorte metodológico, porém, não afasta as considerações e conclusões deste trabalho para debates que tenham por palco outras formas de organização da atividade empresarial.

Diante da possibilidade teórica, como se procurará demonstrar, de reconhecer que alguns bens da companhia, a despeito de serem relacionados ao regime jurídico privado, possuem natureza de bem comum, serão feitas ponderações sobre as implicações jurídicas da possibilidade de thes proporcionar um tratamento especial. Essa análise, que inaugura o Capítulo III deste trabalho, procura definir a melhor forma para a alocação dos chamados feixes de direitos (bundle of rights) a titulares de interesses afetados pela destinação do bem da companhia considerado comum.

Essa reflexão, realizada de acordo com a premissa metodológica do estruturalismo jurídico, pressupõe o enfrentamento das estruturas propriedade e empresa, o que demanda a sua análise a partir do prisma do Direito e Economia de algumas importantes questões relacionadas ao direito societário, com o intuito de estabelecer as bases conceituais utilizadas nas discussões realizadas posteriormente. Nesse contexto, reconhece-se a propriedade como uma forma de internalização de externalidades, com o intuito de reduzir custos de transação e maximizar a eficiência relacionada à destinação do respectivo bem. 
Já dentre as temáticas relacionadas ao direito societário, destaca-se a discussão acerca da definição do interesse social que deve ser perseguido pela companhia, cotejando as bases das correntes contratualistas e institucionalistas. Neste ponto, alguns comentários de cunho metodológico são necessários.

O estudo sobre o interesse social é realizado, em primeiro lugar, por se entender que a discussão sobre a destinação ou mesmo o tratamento jurídico de um bem da companhia pressupõe enfrentamento acerca da organização dos interesses por ela afetados. Em segundo lugar, parte-se da premissa de que o debate sobre o interesse social é um ponto de partida relevante para delimitação de quais seriam os interesses a serem tutelados diante do reconhecimento de um bem empresarial como sendo comum.

Diante dessas considerações, adota-se neste trabalho a corrente do institucionalismo integracionista (ou organizativo), que propõe uma solução procedimental para a definição do interesse social, por meio da organização e internalização dos interesses afetados pela atividade empresarial.

Defende-se, contudo, que o interesse social não pode ser considerado exclusivamente sob o aspecto procedimental, devendo existir um substrato material mínimo para a sua delimitação. Dessa forma, sustenta-se que esse substrato material mínimo deve ser a eficiência em seu sentido distributivo, o que pressupõe algumas reflexões acerca da dicotomia entre eficiência alocativa e eficiência distributiva e as teorias de interesse social, enfrentamento que também é realizado no Capítulo III.

Em seguida, com o objetivo de identificar o regramento a ser aplicado a tais bens, aborda-se o conceito de controle empresarial (que não se confunde com o controle societário), de modo a justificar o porquê de os mecanismos para internalização de interesses afetados pela destinação do bem comum da companhia, bem como de os parâmetros relacionados à alocação ótima dos feixes de direitos a ele relacionados, estarem vinculados à organização do controle empresarial.

Feitos esses esclarecimentos conceituais, aborda-se o parâmetro para a alocação dos feixes de direito relacionados a esses bens da companhia, qual seja o "melhor interesse da companhia", o que equivale à realização da atividade empresarial de acordo com a sua função social. 
Como se procurará demonstrar, a observância da função social da empresa não apenas implica o melhor interesse da companhia, como representa a forma de maximizar a eficiência distributiva relacionada à realização da empresa e à destinação do bem empresarial. Dessa forma, em outras palavras, defende-se que o melhor interesse da companhia é atingido na medida em que a atividade empresarial é realizada no sentido de se maximizar a eficiência distributiva decorrente de sua exploração, o que enuncia, por sua vez, a função social da propriedade do bem empresarial. Trata-se, assim, de consequência relacionada ao reconhecimento do substrato material mínimo vinculado ao interesse social, partindo do alinhamento à vertente do institucionalismo integracionista (ou organizativo).

Cumpre repisar desde logo, a despeito da delimitação feita, que a eficiência que se pretende maximizar é a eficiência distributiva, que não pode ser confundida com a denominada eficiência alocativa e que costuma ser vinculada às teorias utilitaristas tradicionais e, por consequência, associada às vertentes contratualistas do interesse social.

Após essas considerações, passa-se a analisar quais seriam os feixes do direito de propriedade relacionados ao bem comum da companhia, bem como as formas para a alocação de tais feixes de direitos. Pretende-se demonstrar que essa alocação, pelas próprias características dos bens comuns, dar-se-ia do modo adequado e eficiente se realizada por meio de soluções autorregulatórias, sejam elas modalidades de autorregulação voluntária ou de autorregulação compulsória.

Essa discussão possibilita a reflexão estrutural sobre os contratos associativos plurilaterais, tidos como o instrumento mais adequado para formalizar essa alocação de feixes de direitos do bem da companhia considerado comum. Isso se dá, pois a forma de instrumentalizar as soluções autorregulatórias são, justamente, estruturas associativas, a exemplo de associações ou outras modalidades de contratos associativos plurilaterais. Importante salientar que 0 contrato associativo plurilateral configura uma forma tradicional de organização de interesses que é dotada de traços pautados no estruturalismo jurídico em razão da finalidade pretendida nesta tese.

Por fim, são elaboradas algumas considerações conclusivas com o objetivo de consolidar as reflexões realizadas no decorrer deste trabalho. 


\section{CONSIDERAÇÕES CONCLUSIVAS}

Este trabalho assumiu por objetivo analisar a possibilidade de considerar determinados bens da empresa como possuindo natureza de bens comuns (common-pool resources ou, simplesmente CPR, para adotar a terminologia cunhada por Elinor Ostrom, que foi agraciada com o Prêmio Nobel de Economia em razão das reflexões propostas sobre a matéria) e, em caso positivo, desenvolver qual seria o tratamento jurídico adequado para promover a gestão desses bens.

A missão não era simples e exigia que a realidade fosse observada por meio de lentes que se afastassem das concepções tradicionais do direito, marcadas pelo positivismo e pelo jusracionalismo, que configuram premissas de concepção da ciência do direito que tendem a levar à manutenção das estruturas de poder, apresentando certo distanciamento com mudanças estruturais efetivas. Afinal, a proposta de alteração da realidade demanda o enfrentamento das premissas mais arraigadas do objeto estudado, tal como ocorre, justamente, com o positivismo e com o racionalismo jurídico.

Para tanto, em um primeiro momento, preocupou-se com a apresentação das características dos bens comuns, devendo-se entender a expressão como um atributo associado à natureza de determinados bens e que independe de titularidade de domínio formalmente reconhecida pelo ordenamento jurídico, tampouco do regime jurídico tradicionalmente aplicado em relação a esse bem. Nesse contexto, valendo-se da tese desenvolvida por Elinor Ostrom, verificou-se que a discussão relacionada aos bens comuns pressupõe a insuficiência da clássica diferenciação entre bens públicos e bens privados, distinção que fora sobretudo difundida por Paul Samuelson.

Nesse sentido, os bens comuns são caracterizados pelo alto grau de subtração (ou subtrabilidade) de uso e pelo alto grau de dificuldade de exclusão dos titulares afetados por esse bem. Ou seja, ao mesmo tempo em que o uso por um indivíduo impede ou dificulta o uso pelos demais, há grande dificuldade de impedir o acesso (e consequentemente o uso) desse bem pelos indivíduos que são afetados pela sua destinação.

Essas características, não se pode negar, são normalmente associadas aos bens do meio ambiente em razão de seus atributos físicos, existindo, porém, a 
possibilidade reconhecida de ampliação da aplicação desse conceito. Como analisado no decorrer deste trabalho, a própria Ostrom chega a sustentar a adoção do conceito de comum a bens criados pelo homem, sendo recorrendo na doutrina a sua vinculação a praças públicas ou mesmo ao conhecimento (os knowledge commons), o que configura um tema extremamente caro diante da recorrente tentativa de apropriação de fontes de informação, cujo acesso pela coletividade é essencial para o desenvolvimento.

Para ilustrar essas premissas e os atributos corriqueiramente associados aos bens com natureza de comum, foram apresentados três exemplos reais em que essa temática pode ser desenvolvida: os sistemas de irrigação no Nepal, as terras comuns em Törbel, na Suíça, e os manguezais nos quais ocorre o extrativismo de mangaba no Nordeste do Brasil.

Importante destacar que os dois primeiros cenários apresentados foram estudados por Elinor Ostrom e por ela retratados em suas obras, bem como revisitados por outros autores que tratam sobre o tema. O terceiro cenário relatado decorre de experiência empírica observada em trabalho sociológico desenvolvido por pesquisadores brasileiros.

Partindo dessas experiências e das já mencionadas caraterísticas dos comuns, foi proposta a reflexão acerca da possibilidade de estender esse conceito a alguns bens de titularidade da companhia, destinados, assim, à realização da atividade empresarial.

Esse enfrentamento por si só justifica a afirmação do porquê de a missão desta tese ter sido árdua. $O$ conceito de bem comum ainda está em construção e passa por constante revisitação, conforme se extrai do material bibliográfico apresentado no decorrer das páginas deste trabalho. Ao se propor a ampliação desse uso para um ambiente tão vinculado a resultados econômicos e ao apelo pela lucratividade, pretende-se uma quebra de paradigmas e, consequentemente, uma análise crítica das estruturas relacionadas a tais bens, quais sejam, a propriedade e a empresa.

Justifica-se, assim, o motivo pelo qual se devolveu durante o Capítulo I desta tese a concepção aqui adotada de estruturalismo jurídico. Afinal, entendeu-se como relevante apresentar ao leitor a premissa metodológica incorporada na proposta de extensão do conceito de comum para alguns bens empresariais, o que poderia 
enunciar a classificação de common empresarial, que foi a denominação cunhada para os fins deste trabalho.

Dessa forma, foi possível verificar que alguns bens da companhia possuíam as mesmas características observadas nos demais bens caracterizados como comuns, quais sejam, o alto grau de subtrabilidade de uso e o alto grau de dificuldade de exclusão, devendo-se, assim, considerar que tais bens possuem, por lógica e coerência, natureza de comum.

A título exemplificativo foram mencionadas brevemente algumas experiências de cidades operárias (ou company towns) nas quais uma planta industrial poderia ser caracterizada como bem comum. Ou mesmo, é possível cogitar que as barragens de rejeitos de minérios de Fundão, localizada em Mariana (MG) e de titularidade da Samarco Mineração S.A. e a localizada no Córrego do Feijão, em Brumadinho (MG) e de titularidade da Vale S.A. são bens com natureza de comum. Isso se dá, pois o critério para a caracterização da sua natureza não guarda relação necessariamente com seus aspectos físicos, mas sim com a necessidade de acesso (econômico, jurídico ou social) pelos titulares de interesses afetados pela destinação desses bens.

Ora, diante desse cenário, uma vez que a determinados bens da empresa é possível estender tais atributos - o que se admitiu como hipótese excepcional, uma vez que nem todo bem integrante do estabelecimento empresarial possui natureza de comum -, deve-se aplicar a eles tratamento análogo ao adotado em relação a qualquer common.

Note-se nesse sentido que se repisa a diferença entre a natureza do bem e o regramento a ele aplicado. Essa assertiva demandou analisar, justamente, as implicações jurídicas do reconhecimento de um bem da companhia como possuindo natureza de comum, sendo caracterizado, assim, como common empresarial.

Nesse âmbito, parte-se do pressuposto de que a solução para a melhor gestão desses bens demanda uma intervenção estrutural, pautadas nos ditames do chamado estruturalismo jurídico, cujas premissas conceituais foram apresentadas no decorrer do Capítulo I, servindo como pano de fundo para reflexões propostas nesta tese. 
Nesse contexto, o estruturalismo jurídico refere-se à crítica e transformação de estruturas formadas historicamente, que levam a relações de dominação e de concentração e manutenção de poder econômico, sem se preocuparem com os valores e interesses envolvidos. O estruturalismo jurídico pressupõe, assim, a valoração dos interesses envolvidos e o afastamento da concepção positivista do direito e da interpretação baseada no racionalismo jurídico, por favorecerem a manutenção das referidas estruturas de poder.

Essa visão estrutural também teve como pressuposto a promoção de uma solução regulatória que gerasse cooperação entre os envolvidos e favorecesse uma relação de longo prazo, capaz de promover entre os envolvidos a "lógica da ação coletiva". Afinal, esses pressupostos são importantes já que, quanto maior a cooperação, menor a assimetria de informação entre os titulares dos interesses envolvidos e, consequentemente, os custos de transação são reduzidos, o que implica, por sua vez, o incentivo a relações de longo prazo marcadas por maior eficiência. Forma-se, em outras palavras, um círculo vicioso positivo.

Diante dessas premissas, passou-se a enfrentar as estruturas relacionadas ao bem de titularidade de uma companhia com natureza de comum. As estruturas eleitas foram, em um primeiro momento, a propriedade e a empresa, com o intuito de propor uma matriz regulatória para a gestão do bem da companhia com esses atributos. Para isso, algumas questões preliminares foram enfrentadas.

Em primeiro lugar, esclareceu-se que as discussões e soluções propostas eram compatíveis com qualquer uma das teorias de interesse social tradicionalmente estudadas, apesar de expressamente ter se adotado neste trabalho a vertente do institucionalismo integracionista (ou organizativo), que propõe uma solução procedimental para a determinação do interesse social. Defende-se, porém, que essa solução procedimental deve ter um substrato material mínimo, qual seja, a promoção de eficiência distributiva. A discussão sobre o interesse social justifica-se, já que a destinação de um bem da companhia, como no caso concreto, pressupõe a reflexão sobre o seu interesse.

Importante destacar que, das reflexões realizadas, exsurgiu a defesa pela compatibilidade entre a adoção de um racional pautado pelas premissas de Law \& Economics e a concepção integracionista de interesse social. Esse posicionamento, a despeito de se afastar daquele normalmente propagado pela 
melhor doutrina, decorre justamente da adoção do conceito de eficiência distributiva.

Em segundo lugar, definiu-se como âmbito do debate proposto o controle empresarial, entendido como um direito subjetivo da companhia e que compreende a destinação em sentido amplo de seus bens e direitos. Essa premissa pressupôs, por sua vez, a diferenciação entre as estruturas referidas como controle empresarial e como controle societário, tidas como autônomas para os fins deste trabalho. Nesse sentido, a propriedade dos bens da companhia representa uma das formas de manifestação do controle empresarial.

Feitos esses esclarecimentos, partindo do conceito econômico de propriedade como uma forma de internalização de externalidades e do reconhecimento da insuficiência da definição jurídica de propriedade prescrita no Código Civil, enfrentou-se, em uma abordagem baseada nos preceitos do novo estruturalismo jurídico, a estrutura propriedade. Atestou-se, assim, a necessidade de reconhecer que a propriedade é composta por diversos feixes de direitos (bundle of rights), os quais podem ser alocados para os diferentes titulares de interesses afetados pela destinação de referido bem. Houve, assim, a necessidade de delimitar qual seria o parâmetro utilizado para orientar a alocação desses feixes de direitos (bundle of rights), sempre tendo em mente que o bem sob análise é empresarial e tem como escopo o lucro.

Nesse contexto, defendeu-se que o parâmetro que deve ser utilizado para a alocação desses feixes de direitos relacionados ao bem empresarial com natureza de comum seria o melhor interesse da companhia. Dessa forma, o melhor interesse da companhia, por sua vez, remetendo-se à discussão sobre interesse social realizada previamente, é tido como presente quando o bem é destinado de acordo com a sua função social, observado, é claro, o intuito lucrativo inerente à atividade empresarial.

Destarte, definiu-se que a função social do bem empresarial é observada na medida em que se busca a maximização da eficiência distributiva, com nítido caráter publicista e em reconhecimento da sociedade anônima como um instrumento de política econômica e como uma forma de promoção de direitos sociais, tendo em vista a superação do subdesenvolvimento. 
Diante disso, foi imperioso procurar delimitar quais seriam os feixes de direitos relacionados ao bem da companhia com natureza de bem comum, para, então, propor uma forma para a alocação desses feixes e para a gestão e destinação diferenciada de tal bem.

Apesar de ter sido apresentada uma matriz que se entende aplicável a todos os bens considerados como possuidores de natureza de bem comum, a determinação dos feixes de direitos dependerá de cada caso concreto. De igual modo, a própria delimitação dos interesses afetados e que devem ser considerados nessa alocação depende das características fáticas do bem, muito embora seja interessante a identificação de dispositivos declaratórios de interesses para a sua delimitação, conforme evidenciado no decorrer deste trabalho.

Essa ressalva é de extrema importância, já que em nenhum se propaga nesse trabalho a defesa por uma publicização do bem empresarial, tampouco se sustenta que a solução regulatória para esses commons empresariais deva ser a adoção de um regime de propriedade comunal. A companhia - e por consequência seus bens - possui inerente intuito lucrativo, o que não pode deixar de ser considerado sob pena de amplo desvirtuamento do próprio Direito Empresarial.

Sendo assim, em relação à forma de alocação desses feixes de direitos, partiu-se da necessidade de pautá-la em uma estrutura que favorecesse novamente - a cooperação entre os indivíduos e a relação de longo prazo entre eles. Tais características aproximam-se das soluções relacionadas à autorregulação, seja na modalidade de autorregulação voluntária ou de autorregulação compulsória, conforme distinção feita no decorrer deste trabalho e caracterizada pela presença ou não da imposição do regulador.

Já em relação à instrumentalização, o contrato associativo plurilateral exsurge como instrumento propício para regular esses interesses e promover a gestão desse common empresarial, podendo até mesmo ser responsável pela alocação dos feixes de direitos relacionados à propriedade empresarial.

Dessa forma, o contrato associativo plurilateral proporciona, em razão do "relevo" ou "efeito real" que lhe é inerente, a oponibilidade perante terceiros das disposições nele previstas, bem como a possibilidade de composição de um conglomerado composto por de facto property rights e de jure property rights, em 
consonância com o reconhecimento do direito de propriedade alinhado com as premissas do estruturalismo jurídico.

Ademais, essa visão do contrato associativo plurilateral contribui para que essa técnica associativa deixe de ser apenas o instrumento para constituição de uma entidade associativa - seja ela uma sociedade, personificada ou não, ou uma associação - e assuma também papel de método para a organização de interesses - o que está associado à função organizacional do contrato associativo plurilateral -, bem como para a internalização de externalidades, vez que não fossem os interesses afetados pela destinação do bem considerado comum considerados no processo decisório para a sua destinação, poderiam ser tratados como externalidades.

Consequentemente, a solução jurídica proposta e que parte de preceitos pautados no novo estruturalismo jurídico caminha no mesmo sentido da solução econômica dela decorrente, sustentada na maximização de eficiência distributiva e representando uma forma de promoção de interesses sociais, com redução da desigualdade, mitigação dos efeitos deletérios da assimetria informacional e promoção de uma verdadeira alternativa que vise à superação do subdesenvolvimento.

Em tom conclusivo, o objetivo deste trabalho não foi trazer ou responder todos os questionamentos decorrentes do reconhecimento da existência de um common empresarial, mas possibilitar um canal que leve ao enfrentamento de novas composições de interesses e de soluções regulatórias e autorregulatórias decorrentes da validação dessa premissa. Espera-se, assim, que este trabalho possibilite sobretudo novos questionamentos a serem enfrentados e respondidos. 


\section{REFERÊNCIAS BIBLIOGRÁFICAS}

AKERLOFF, George A. The Market for Lemons: Quality Uncertainty and the Market Mechanism. In: The Quarterly Journal of Economics 84, Vol. 3. Aug, 1970. pp. 488500

ALCHIAN, A.; DEMSETZ, H. Production, information costs and economic organizations. In: The American Economic Review, vol. 62, 1972 pp. 777-795

ALDANA, Clemencia I. M. La cooperación: estrategia para la sostenabilidad de los recursos. In: Dimensión Empresarial. Vol. 14, No. 2. pp. 25-38

ALSTON, Lee J.; HARRIS, Edwyna; BUELLER, Bernardo. De facto and de jure property rights: land settlement and land conflict on the Australian, Brazilian and U.S. frontier. NBER Working Paper No. 15264. Aug/2009. Disponível em: <http://www.nber.org/papers/w15264>. Acesso em: 13.03.2019

ALSTON, Lee. J.; LIBECAP, Gary D.; MUELLER, Bernardo. Titles, Conflict, and Land Use: The Development of Property Rights and Land Reform on the Brazilian Amazon Frontier. Ann Arbor: University of Michigan Press, 1999

ANTUNES, José A. Engrácia. Os Grupos de Sociedades - Estrutura e Organização Jurídica da Empresa Plurissocietária. Coimbra: Almedina: 1993

ARENDT, Hannah. A Condição Humana. Trad. de Roberto Raposo. Lisboa: Relógio d'Água Editores, 2001.

ARRUÑADA, Benito. Property as sequential exchange: The forgotten limits of private contract. Disponível em: https://ssrn.com/abstract=2879827. Acesso em: 03.06.2018 
ASCARELLI, Tullio. Princípios e Problemas das Sociedades Anônimas. In: Problemas das Sociedades Anônimas e Direito Comparado. São Paulo: Saraiva, 1945

ASCARELLI, Tullio. O Contrato Plurilateral. In: ASCARELLI, Tullio. Problemas das Sociedades Anônimas e Direito Comparado. $2^{\underline{a}}$ Ed. São Paulo: Editora Saraiva, 1969. pp. 255- 312

ASQUINI, Alberto. I batelli del Reno. In: Revista dele Società. Ano IV. Milano: Giuffrè, 1959. pp. 617-633.

ASQUINI, Alberto. Perfis da Empresa. Trad. de Fábio Konder Comparato. In: Revista de Direito Mercantil, v. 104, out-dez, 1996

ASQUINI, Alberto. Profili dell'impresa. In: Rivista de Diritto Commerciale. Vol. XLI, I, 1943

AXELROD, Robert, The Evolution of Cooperation. New York: Basic Books, Inc, 1984

BAINBRIDGE, Stephen M. Director Primacy: The Means and Ends of Corporate Governance. University of California, Los Angeles - School of Law - Research Paper Series - Research Paper No. 02/06. Disponível em: <http://ssrn.com/abstract=300860>. Acesso em 07.03.2019

BAIRD, Douglas G; GERTNER, Robert H.; PICKER, Randal C. Game Theory and the Law. Harvard University Press, 1998

BARRETO FILHO, Oscar. Teoria do estabelecimento comercial: fundo de comércio ou fazenda mercantil. São Paulo: Saraiva, 1988

BENKLER, Yochai. The Commons as a Neglected Factor of Information Policy. p. 2. Disponível em: <http://www.benkler.org/commons.pdf>. Acesso em: 10.03.2019 
BENTHAM, Jeremy. An Introduction to the Principles of Morals and Legislation. Kitchner: Batoche Books, 2000. pp. 14-27

BERLE JR., Adolf A. Corporate Powers as Powers in Trust. In: Harvard Law Review, Vol. 44, No. 7, may/1931. pp. 1040-1074

BERLE JR. Adolf. For Whom Corporate Managers Are Trustees: a Note. In: Harvard Law Review. Vol. 45, 1932. pp. 1365-1372

BLACKBURN, Simon. Oxford Dictionary of Philosofy. 2nd Edition Revised. Oxford: Oxford University Press, 2008

BLAIR, Margaret M.; STOUT, Lynn A. A Team Production Theory of Corporate Law. In: Virginia Law Review. Vol. 85, No. 2, mar./1999. pp. 248-328

BLUMBERG, Phillip I. The Corporate Entity in the Era of Multinational Corporations. In: Delaware Journal of Corporate Law, Vol. 15, No. 2, 1990. pp. 283-375

BOBBIO, Norberto. O Positivismo Jurídico: Lições de Filosofia do Direito. Compiladas por Nello Morra. Trad. e notas Márcio Pugliesi, Edson Bini e Carlos E. Rodrigues. São Paulo: Ícine, 1999

BOBBIO, Norberto. Teoria do ordenamento jurídico. 10ª Ed. Brasília: Universidade de Brasília, 1999

BOBBIO, Norberto. Teoria Geral do Direito. Trad. Denise Agostinetti. $3^{a}$ ed. São Paulo: Martins Fontes, 2010

BUCHANAN, James M. An Economic Theory of Clubs. In: Economica, New Series, Vol. 32, No. 125. Feb., 1965. pp. 1-14 
BUDZINSKI, Oliver. Pluralism of Competition Policy Paradigms and the Call for Regulatory Diversity. In: Philipps-University of Marburg Volkswirtschaftliche Beitraege, No. 14/2003, oct. 2003. Disponível em: $<$ https://ssrn.com/abstract=452900>. Acesso em 04.03.2019

CALABRESI, Guido. The Pointless of Pareto: Carrying Coase Further. In: Yale Law Journal Vol. 100, mar./1991. pp. 1211-1237

CARVALHOSA, Modesto. A Nova Lei das Sociedades Anônimas - Seu Modelo Econômico. 2ª Ed. Rio de Janeiro: Paz e Terra, 1977

CARVALHOSA, Modesto. A Nova Lei das S/A. São Paulo: Saraiva, 2002

CATEB, Alexandre Bueno; OLIVEIRA, Fabrício de Souza. Breves anotações sobre a função social da empresa. In: Revista da AMDE (Associação Mineira de Direito Empresarial) v.2., jul. 2009. Disponível em: <http://www.revista.amde.org.br/index.php/ramde/article/view/25>. Acesso em: 03 mar. 2019)

CEREZETTI, Sheila Christina Neder. A Recuperação Judicial de Sociedade por Ações - O Princípio da Preservação da Empresa na lei de Recuperação e Falência. São Paulo: Malheiros, 2002

CHAMPAUD, Claude. Le pouvoir de Concentration de la Société par Actions. Paris: Sirey, 1962

CISTAC, Gilles. A Instituição Administrativa e as Teorias do Pluralismo Jurídico. In: Prim@ Facie. Vol. 12. No. 23. João Pessoa, 2013

COASE, Ronald H. The Nature of the Firm. In: Economica, New Series, Vol. 4, No. 16, Nov., 1937. pp. 386-405 
COASE, Ronald H. The problem of social cost. In: The Journal of Law \& Economics, vol. III, October 1960

COMPARATO, Fábio Konder. Estado, Empresa e Função Social. In: Revista dos Tribunais, Vol. 732. São Paulo: RT, 1996. pp. 38-46

COMPARATO, Fábio Konder. Função social da propriedade dos bens de produção. In: Revista de Direito Mercantil, Industrial, Econômico e Financeiro. Ano XXV, no 63, jul/set 1986. pp.71-79

COMPARATO, Fábio Konder. O direito e o avesso. In: Estudos Avançados. v. 23, n. 67. São Paulo, jan. 2009. pp.6-22

COMPARATO, Fábio Konder; SALOMÃO FILHO, Calixto. O Poder de Controle na Sociedade Anônima. $6^{\underline{a}}$ edição revista e atualizada. Rio de Janeiro: Ed. Forense, 2014

COOTER, Robert; ULEN, Thomas. Law \& Economics. 6th Edition. Berkeley Law Books, 2016

COUTINHO, Carlos Nelson. O Estruturalismo e a Miséria da Razão. 2ª Edição. São Paulo: Editora Popular, 2010

DAVIS, Otto. A.; WHINSTON, Andrew B. On the distinction between public and private goods. In: The American Economic Review. Vol. 57, No. 02. Papers and Proceedings of the Seventy-ninth Annual Meeting of the American Economic Association. May, 1967. pp. 360-373

DAWES, R. M. Formal Models of Dilemmas in Social Decision Making. In: KAPLAN, M. F.; SCHWARTZ, S. Human Judgement and Decision Processes: Formal and Mathematical Approaches. New York: Academic Press, 1975. pp. 87-108 
DEMSETZ, Harold. Toward a Theory of Property Rights. In: The American Economic Review, Vol. 57. No. 2. Papers and Proceedings of the 79th Annual Meeting of the American Economic Association. May, 1967. pp. 347-359

DI PIETRO, Maria Sylvia Zanella. Direito Administrativo. 24 ed. São Paulo: Atlas, 2011

DODD JR., Merrick. For Whom Are Corporate Managers Trustees? In: Harvard Law Review. Vol. XLV, No. 7, may/1932. pp. 1145-1163

DWORKIN, Ronald. Taking Rights Seriously. 17 Ed. Cambridge: Harvard University Press, 1999

DWORKIN, Ronald. Uma Questão de Princípio. Trad. Luís Carlos Borges. São Paulo: Martins Fontes, 2001

EISENBERG, Melvin Aron. The Structure of Corporation Law. In: Columbia Law Review, Vol.89, 1989. pp. 1461-1525

ELHAUGE, Einer. Sacrificing Corporate Profits in the Public Interest. In: The New York University Law Review. Vol. 80, No. 3, jun./2005. pp. 733-869

FONSECA, Pedro Cezar Dutra. A Política e seu Lugar no Estruturalismo: Celso Furtado e o Impacto da Grande Depressão no Brasil. In: Revista EconomiA, Selecta, Vol. 10, No. 4, dez/2009, Brasília (DF). pp. 867-885

EASTBROOK, Frank H.; FISCHEL, Daniel R. The Economic Structure of Corporate Law. Cambridge: Harvard University Press, 1991

EGGERTSSON, T. Economic Behavior and Institutions. Cambridge Surveys of Economic Literature. Cambridge: Cambridge University Press, 1990 
FEENY, David; HANNA, Susan; MCEVOY, Arthur F. Questioning the Assumption of the "Tragedy of the Common" Model of Fisheries. In: Land Economics. Vol. 72, No. 2, may/1996, pp. 187-205

FORGIONI, Paula A. Análise Econômica do Direito (AED): Paranóia ou Mistificação. In: Revista de Direito Mercantil, Industrial, Econômico e Financeiro. Vol. 139. Ano XLVI (Nova Série). julho-setembro/2005. pp. 242-256

FOSTER, Sheila R. Collective Action and the Urban Commons. In: Notre Dame Law Review. Vol. 87, No. 1. pp. 57-134. Disponível em: <http://ssrn.com/abstract=1791767>. Acesso em: 12.03 .2019

FRANÇA, Erasmo Valladão Azevedo e Novaes. Conflito de Interesses nas Assembléias de S.A. (e outros escritos sobre conflito de interesses). $2^{a}$ ed. São Paulo: Malheiros Editores, 2014

FRANÇA, Erasmo Valladão Azevedo e Novaes. Invalidade das Deliberações de Assembléia das S.A. São Paulo: Malheiros, 1999

FRANÇA, Erasmo Valladão Azevedo e Novaes; ADAMEK, Marcelo Vieira von. Affectio societatis: um conceito jurídico superado no moderno direito societário pelo conceito de fim social. In: Revista de Direito Mercantil, Industrial, Econômico e Financeiro. n. 149/150. jan-dez/2008. São Paulo: Malheiros Editores, 2008. pp. 108130

FURTADO, Celso. Brasil: a construção interrompida. $2^{\underline{a}}$ Ed. Rio de Janeiro: Paz e Terra, 1992

FURTADO, Celso. Formação econômica do Brasil. 32ª Ed. São Paulo: Companhia Editora Nacional, 2003

FURTADO, Celso. Teoria e política do desenvolvimento econômico. São Paulo: Abril Cultural, 1983 
GALGANO, Francesco. Diritto Commerciale - Le Società. 3르 Ed. Bologna: Zanichelli, 1987

GARCIA, Afrânio; PALMEIRA, Moacir. Traces of the Big House and the Slave Quarters: Social Transformation in Rural Brazil During the Twentieth Century. In: SACHS, Igancy; WILHEIM, Jorge; PINHEIRO, Paulo Sérgio (Eds.). Brazil: A Century of Change. The University of North Carolina, 2009. pp. 20-54

GAREA, Rafael Colina. La Función Social de la Propriedad Privada em la Constitución Española de 1978. Barcelona: J. M. Bosch Editor, 1997

GODINHO, André Osório. Função social da propriedade. In: TEPEDINO, Gustavo (Coord.). Problemas de direito civil constitucional. Rio de Janeiro: Renovar, 2002

GOMES, Orlando. Contratos. 14 ed. Rio de Janeiro: Forense, 1994

GORDON, H. Scott. The Economic Theory of a Common-Property Resource: The Fishery. In: The Journal of Political Economy. Vol. 62, No. 2, apr./1954. pp. 124-142

GRAFSTEIN, Robert. Structure and Structuralism. In: Social Science Quarterly, Vol. 63, No. 4, December/1982. pp. 617-633

GRAFTON, R. Q.; SQUIRES, Dale; FOX, Kevin J. Private property and economic efficiency: a study of a common-pool resource. In: Journal of Law \& Economics. Vol. XLII, October, 2000. pp. 679-713

GRAU, Eros Roberto. A Ordem Econômica na Constituição de 1988. 6ª ed. São Paulo: Malheiros, 2001

GUERREIRO, José Alexandre Tavares. Sociologia do Poder na Sociedade Anônima. In: Revista de Direito Mercantil, Industrial, Econômico e Financeiro. Ano XXIX, n. 77, jan.-mar./1990. pp. 50-56 
GULATI, Gaurang Mitu; KLEIN, William A.; ZOLT, Eric M. Connected Contracts. In: UCLA Law Review, Vol. 47, 2000. pp. 887-948. Disponível em: $<$ https://ssrn.com/abstract=217590>. Acesso em 04.03.2019

HANSMANN, Henry. The ownership of enterprise. Cambridge: Belknap Press, 1996 HARDIN, Garrett. The Tragedy of the Commons. In: Science, New Series. Vol. 162. No. 3859 (Dec. 13, 1968). pp. 1243-1248

HAURIOU, Maurice. A instituição e o direito estatutário. Trad. Evandro Fernandes de Pontes. In: Revista de Direito das Sociedades e dos Valores Mobiliários. No. 4. São Paulo: Almedina, nov./2016. pp. 148-214

HAUSMANN, Fritz. Vom Aktienwesen und vom Aktienrecht. Mannheim: J. Bensheimer, 1928

HERMANN, Jennifer. Auge e Declínio do Modelo de Crescimento com Endividamento: o II PND e a Crise da Dívida Externa. In: GIAMBIAGI, Fábio; VILLELA, André; DE CASTRO, Lavínia Barros; HERMANN, Jennifer (Orgs.). Economia Brasileira Contemporânea: 1945-2010. Rio de Janeiro: Elsevier, 2011. pp. 73-96

HERMANN, Jennifer. Reformas, Endividamento Externo e o "Milagre" Econômico (1964-1973). In: GIAMBIAGI, Fábio; VILLELA, André; DE CASTRO, Lavínia Barros; HERMANN, Jennifer (Orgs.). Economia Brasileira Contemporânea: 1945-2010. Rio de Janeiro: Elsevier, 2011. pp. 49-72

HESS, Charlotte; Indiana University, Bloomington. A Comprehensive Bibliography of Common-Poll Resources. Workshop in Political Theory and Policy Analysis, Indiana University, Bloomington, Ind, 1999 
HESS, Charlotte; OSTROM, Elinor. Understanding Knowledge as a Commons, From Theory to Practice, The MIT Press, Cambridge, Massachusetts Institute of Technology, London, England, 2007

HEWLETT Sylvia Ann. Dynamics of Economic Imperialism: The Role of Foreign Investment in Brazil. In: Latin American Perspectives, Vol. 2, No. 1, Confronting Theory and Practice, Spring, 1975. pp. 136-148

HIRSCH, Werner Z. Law and Economics: An Introductory Analysis. 3rd Ed. San Diego: Academic Press, 1999

HOPT, Klaus J. The German Law and Experience with the Supervisory Board. European Corporate Governance Institute (ECGl) - Law Working Paper No. 305/2016. Disponível em: <https://ssrn.com/abstract=2722702>. Acesso em: 13.03 .2019

IRUJO, José Miguel Embid. Algunas Reflexiones sobre los Grupos de Sociedades y su Regulación Jurídica. In: Revista de Direito Mercantil, Industrial, Econômico e Financeiro. Vol. 23, No. 53, jan.-mar./1984. pp. 18-40

JACKSON, Gregory; HÖPNER, Martin; KURDELBUSCH, Antje. Corporate Governance and Employees in Germany: Changing Linkages, Complementarities, and Tensions. RIETI Discussion Paper No. 04-E-008. Disponível em: $<$ https://ssrn.com/abstract=2579932>. Acesso em: 13.03.2019

JAMESON Kenneth P. Latin American Structuralism: A Methodological Perspective. In: World Development. Vol. 14, No. 2, feb./1986. pp. 223-232

JENSEN, M; MECKLING, W. Theory of the firm: Managerial Behavior, Agency Costs and Ownership Structure. In: Journal of Financial Economics, vol. 3, 1976. pp. $305-360$ 
JOHNSTON, Jason S. Law, Economics and Post-Realist Explanation. Working Paper No. 137 - Post Realist. Yale Law School Program in Civil Liability, 1990

KLEIN, Vinicius; KRASINSKI, Rafaella. Instituições e Mudança Institucional. In: RIBEIRO, Marcia Carla Pereira; DOMINGUES, Victor Hugo; KLEIN, Vinicius. Análise Econômica do Direito: justiça e desenvolvimento. Curitiba: Editora CRV, 2016. pp. 159-164

LAMY FILHO, Alfredo. A Função Social da Empresa e o Imperativo de sua Reumanização. In: Revista de Direito Administrativo - RDA. oㅜ 190, out/dez 1992. pp. $54-60$

LAMY FILHO, Alfredo; PEDREIRA, José Luiz Bulhões. A Lei das S.A.: Pressupostos, Elaboração, Aplicação. Rio de Janeiro: Renovar, 1992

LAMY FILHO, Alfredo. A reforma da Lei de Sociedades Anônimas. In: Revista de Direito Mercantil. no 7. pp.123-158

LAUTENSCHLEGER JR., Nilson. Relato breve sobre Walther Rathenau e sua obra: 'A Teoria da Empresa em Si'. In: Revista de Direito Mercantil, Industrial, Econômico e Financeiro. Ano XLI, No. 128, out-dez/2002. pp. 199-202

LEÃES, Luiz Gastão Paes de Barros. Comentários à Lei das Sociedades Anônimas. vol. 2. São Paulo: Saraiva, 1980

LEÃES, Luiz Gastão de Barros. Conflito de interesses. In: LEÃES, Luiz Gastão Paes de Barros. Estudos e pareceres sobre sociedades anônimas. São Paulo: Revista dos Tribunais, 1989

LEE, lan B. Efficiency and Ethics in the Debate About Shareholder Primacy. University of Toronto Legal Studies Series, Research Paper No. 15-05, oct./2005. Disponível em: <http://ssrn.com/abstract=778765>. Acesso em 07.03.2019 
LERNER, Abba P. Utilitarian Marginalism (Nozick, Rawls, Justice, and Welfare). In: Eastern Economic Journal. Vol. 4. No. 1. pp.51-65

LESSIG, Lawrence. Code and the Commons. Keynote, given at a conference on Media Convergence Fordham Law School, Feb./1999. p. 2. Disponível em: <https://cyber.harvard.edu/works/lessig/Fordham.pdf>. Acesso em: 10.03.2019

LEYENS, Patrick C. German Company Law: Recent Developments and Future Challenges. In: German Law Journal. Vol 06, No. 10, 2015. pp. 1407-14017

LITMAN, Jessica. The Public Domain. p. 8-9. Disponível em: $<$ https://www.law.duke.edu/pd/papers/litman_background.pdf>. Acesso em: 10.03.2019

LOPES, Ana Frazão de Azevedo. Empresa e Propriedade - função social e abuso de poder econômico. São Paulo: Quartier Latin, 2006

LOUREIRO, Francisco Eduardo. A Propriedade como Relação Jurídica Complexa. Rio de Janeiro: Renovar, 2003

LUMIA, Giuseppe. Principios de Teoría e Ideología del Derecho. Trad. Alfonso Ruiz Miguel. Santiago: Ediciones Olejnik, 2017

MARGOLIS, Stephen E. Two Definitions of Efficiency in Law and Economics. In: Journal of Legal Studies - University of Chicago, vol. XVI, June 1987, pp. 473-474

MATIAS, João Luis Nogueira. A função social da empresa e a composição de interesses na sociedade limitada. Tese (Doutorado em Direito) - Faculdade de Direito da Universidade de São Paulo. São Paulo, 2009

MATTIETTO, Leonardo. A renovação do direito de propriedade. In: Revista de Informação Legislativa. Brasília, ano 42, n. 168, out./dez. 2005. pp. 189-196 
MARCONDES MACHADO, Sylvio. Da Atividade Negocial: Empresários e Sociedade. In: Problemas de Direito Mercantil. São Paulo: Max Limonad, 1970

MARTINS, Fran. Comentários à Lei das Sociedades Anônimas. $4^{a}$ Ed. Rio de Janeiro: Forense, 2010

MCGAUGHEY, Ewan. The Codetermination Bargains: The History of German Corporate and Labour Law. Law Society Economy (LSE) Working Papers 10/2015, London School of Economics and Political Science. Disponível em: < http://ssrn.com/abstract=2579932>. Acesso em 05.03.2019

MEDAUAR, Odete. Regulação e Auto Regulação. In: Revista de Direito Administrativo. Rio de Janeiro, 228, Abr./Jun. 2002. pp. 123-128

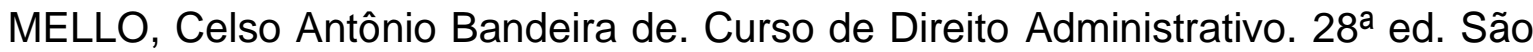
Paulo: Malheiros Editores, 2011

MIRAGEM, Bruno. O artigo 1228 do Código Civil e os deveres do proprietário em matéria de preservação do meio ambiente. In: Cadernos do Programa de Pósgraduação em Direito da UFRS. Porto Alegre, v. III, n. VI, mai./2005. pp. 21-45

MISSIO, Fabrício J.; JAYME JR., Frederico G. Estruturalismo e Neoestruturalismo: Velhas Questões, Novos Desafios. In: Análise Econômica, Ano 30, N. 57, mar./2012, Porto Alegre. pp. 205-230

MUNHOZ, Eduardo Secchi. Empresa contemporânea e direito societário - poder de controle e grupos societários. São Paulo: Juarez de Oliveira, 2002

NETTING, R. McC. What Alpine Peasants Have in Common: Observations on Communal Tenure in a Swiss Village. Human Ecology 4, 1976. pp. 135-146

NORTH, Douglass C. Economic Performance Through Time. In: The American Economic Review. Vol. 84, No. 3, jun./1994. pp. 359-368 
NORTH, Douglass C. Institutions, Institutional Change and Economic Performance. New York: Cambridge University Press, 1990

NUNES, Márcio Tadeu Guimarães. Função de Impacto das Sociedades Anônimas no Sistema Jurídico e Econômico Brasileiro. In: FINKELSTEIN, Maria Eugenia Reis; PROENÇA, José Marcelo Martins. Direito Societário: sociedades anônimas. Série GVlaw. São Paulo: Saraiva, 2007. pp. 1-37.

OLIVEIRA, Francisco E. B.; BELTRÃO, Kaizô I.; PASINATO, Maria Teresa de M.; FERREIRA, Mônica Guerra. A Rentabilidade do FGTS. Rio de Janeiro: IPEA, 1998

OLSON, Mancur. The Logic of Collective Action - Public Goods and the Theory of Groups. Cambridge: Harvard University Press, 1965

OLSON, Mancur. The Logic of Collective Action: Public Goods and Theory of Groups. In: In: DAHL, Robert; SHAPIRO, Ian; CHEIBUB, José Antonio. The Democracy Sourcebook. Cambridge: The MIT Press, 2003. pp. 372-380

ORENSTEIN, Luiz; SOCHACZEWSKI, Antonio Claudio. Democracia com desenvolvimento, 1956-1961. In: ABREU, Marcelo de Paiva (Org.). A Ordem do Progresso: dois séculos de política econômica no Brasil. Rio de Janeiro: Elsevier, 2015. Capítulo 8

OSTROM, Elinor. Beyond Markets and States: Polycentric Governance of Complex Economic Systems. Prize Lecture, December 8, 2009

OSTROM, Elinor. Governing the Commons: the evolution of institutions for collective action. California: Cambridge University Press, 1990

OSTROM, Elinor; HESS, Charlotte. Ideas, Artifacts, and Facilities: Information as a Common-Pool Resource. In: Law and Contemporary Problems. Vol. 66, winter/spring 2003. pp. 111-145 
OSTROM, Elinor; SCHLAGER, Edella. Property-Rights Regimes and Natural Resources: A Conceptual Analysis. In: Land Economics. Vol. 68. No. 3, aug./1992. pp. 249-262

PENTEADO, Mauro Rodrigues. Dissolução e Liquidação de Sociedades. 2a Ed. São Paulo: Saraiva, 2000

PEREIRA, Caio Mário da Silva. Direito Civil - alguns aspectos da sua evolução. Rio de Janeiro: Forense, 2001

PERLINGIERI, Pietro. Introduzione allá Problemática della Proprietá. Camerino: Jovene, 1971

PLOTT, Charles R.; MEYER, Robert A. The Technology of Public Goods, Externalities, and the Exclusion Principle. In: MILLS, Edwin S. (Ed.). Economic Analysis of Environmental Problems. NBER, 1975. pp. 65-94

POLINKSY, A. Mitchell. An Introduction to Law and Economics. Second Edition. Aspen Law \& Business Panel Publishers, 1989

PONTES, Evandro Fernandes de. Os interesses jurídicos nas sociedades de economia mista. In: NORONHA, João Otávio de; FRAZÃO, Ana; MESQUITA, Daniel Augusto (Coords.). Estatuto jurídico das estatais: análise da Lei $\mathrm{n}$ 은 13.303/2016. Belo Horizonte: Fórum, 2017. pp. 419-466

PONTES DE MIRANDA, F. C. Tratado de Direito Privado - Parte Geral - Tomo I Introdução. Pessoas Físicas e Jurídicas. 4ª Ed. São Paulo: RT, 1974

POSNER, R. Economic analysis of law. $2^{\underline{a}}$ ed. Boston/Toronto, 1977

PREBISCH, Raúl. Capitalismo Periferico: Crisis y Transformación. 1aㅡ Ed. México: Fondo de Cultura Económica, 1981 
PREBISCH, Raúl. El Falso Dilema entre Desarrollo Económico y Estabilidad Monetaria. In: Boletin Económico de América Latina, Vol. VI, No. 1, 1961. pp. 1-26

PROENÇA, José Marcelo Martins. Direitos e Deveres dos Acionistas. In: FINKELSTEIN, Maria Eugenia Reis; PROENÇA, José Marcelo Martins. Direito Societário: sociedades anônimas. Série GVlaw. São Paulo: Saraiva, 2007. pp. 3987

PROENÇA, José Marcelo Martins. Função social da sociedade - convivência entre interesse público e interesse privado. In: FILKENSTEIN, Maria Eugênia. PROENÇA, José Marcelo Martins (coords.). Direito Societário: gestão de controle. São Paulo: Saraiva. 2008. Série GVlaw. p. 3-19

RAMOS, André Carvalho. Curso de Direitos Humanos. 4ª Ed. São Paulo: Saraiva, 2017

RAMUNNO, Pedro A. L. Controle Societário e Controle Empresarial: uma análise da influenciação sobre o controle empresarial pelo Estado brasileiro. São Paulo: Almedina, 2017

RAPOPORT, Anatol; CHAMMAH, Albert M.. Prisoner's Dilemma: A Study in Conflict and Cooperation. University of Michigan Press, 1965

RATHENAU, Walther. Do Sistema Acionário - Uma Análise Negocial. (Trad. Nilson Lautenschleger Jr.). In: Revista de Direito Mercantil, Industrial, Econômico e Financeiro. Ano XLI, No. 128, out-dez/2002. pp. 202-223

REALE, Miguel. Teoria Tridimensional do Direito. 5를. São Paulo: Editora Saraiva, 2003

RIBEIRO, Marcia Carla Pereira; ROCHA, Lara Bonemer Azevedo da. Eficiência e Justiça. In: RIBEIRO, Marcia Carla Pereira; DOMINGUES, Victor Hugo; KLEIN, 
Vinicius. Análise Econômica do Direito: justiça e desenvolvimento. Curitiba: Editora CRV, 2016. pp. 165-170

RIBEIRO, Renato Ventura. Direito de Voto das Sociedades Anônimas. São Paulo: Quartier Latin, 2009

RIPERT, Georges. Aspects juridique du capitalisme moderne. 2ª Ed. Paris: Librarie Générale de Droit et de Jurisprudence, 1951

ROCHA, Cármen Lúcia Antunes. O princípio da função social da propriedade. In: Revista Latino-Americana de Estudos Constitucionais. Belo Horizonte, n. 2, jul./dez. 2003. pp. 543-594

RODRIGUEZ, Octavio. O Estruturalismo Latino-Americano, Rio de Janeiro: Editora Civilização Brasileira, 2009

RUDDLE, Kenneth. Solving the Common-Property Dilemma: Village Fisheries Rights in Japanese Coastal Water. In: Common Property-Resources: Ecology and Community-Based Sustainable Development, 1995. pp. 168-184

SALOMÃO FILHO, Calixto. A Sociedade Unipessoal. São Paulo: Malheiros, 1995

SALOMÃO FILHO, Calixto; FERRÃO, Brisa Lopes de Mello; RIBEIRO, Ivan César. Concentração, Estruturas e Desigualdade: As Origens Coloniais da Pobreza e da Má Distribuição de Renda. Instituto de Direito do Comércio Internacional e Desenvolvimento (IDCID), 2008

SALOMÃO FILHO, Calixto. Direito Concorrencial. São Paulo: Malheiros Editores, 2013

SALOMÃO FILHO, Calixto. Interesse Social: A nova concepção. In: O Novo Direito Societário. 4aㅡ ed. rev. ampl. São Paulo: Malheiros Editores, 2011. pp. 27-52 
SALOMÃO FILHO, Calixto. Novo estruturalismo jurídico: uma alternativa para o direito? In: Revista dos Tribunais, vol. 926. Dezembro, 2012

SALOMÃO FILHO, Calixto. Revolution through law in the economic sphere. SELA (Seminario en Latinoamérica de Teoría Constitucional y Política) Papers. Paper 10. Disponível em http://digitalcommons.law.yale.edu/yls_sela/10, Acesso em 28.02.2019

SALOMÃO FILHO, Calixto. Teoria Crítico Estruturalista do Direito Comercial. São Paulo: Marcial Pons, 2015

SAMUELSON, Paul A. Aspects of Public Expenditure Theories. In: The Review of Economics and Statistics. Vol. 40. No. 4. Nov., 1958. pp. 332-338

SAMUELSON, Paul A. Diagrammatic Exposition of Theory of Public Expenditure. In: The Review of Economics and Statistics. Vol. 37, No. 4. Nov., 1955. pp. 350-356

SAMUELSON, Paul A. The Pure Theory of Public Expenditure. In: The Review of Economics and Statistics, Vol. 36, No. 4. Nov., 1954. pp. 387-389

SANTORO-PASSARELLI, Francesco. Dottrine generali del diritto civile. 9 ed. Napoli: Jovene, 2002

SCHMITZ, Heribert; MOTA, Dalva Maria da; SILVA JÚNIOR, Josué Francisco da. Gestão coletiva de bens comuns no extrativismo da mangaba no nordeste do Brasil. In: Ambiente \& Sociedade. v. XII, n. 2. jul-dez. 2009. pp. 273-292

SCIFONI, Simone. Lugares de Memória Operária na Metrópole Paulistana. In: GEOUSP - espaço e tempo, no 33. São Paulo, 2013. pp. 98-110

SEN, Amartya. The Idea of Justice. Cambridge: The Belknap Press of Harvard University Press, 2009 
SHIVATOKI, Ganesh P.; OSTROM, Elinor. Improving Irrigation Governance and Management in Nepal. ICS Press, 2001

SHIVATOKI, Ganesh P. Management Transfer of Agency-Managed Irrigation Systems in Nepal: Are There Any Lessons To Be Learned from Farmer-Managed Irrigation Systems? Disponível em: <http://publications.iwmi.org/pdf/H015464.pdf>. Acesso em: 01.07.2017.

SINGH, Katar. Managing common pool resources: principles and case studies. Delhi: Oxford University Press, 1994

SMITH, Henry E. Semicommon property rights and scattering in the open fields. In: The Journal of Legal Studies. Vol. 29. No. 1. jan./ 2000. pp. 131-169

SOMMER JR., Alphonse Adam. Whom should the corporation serve? The BerleDodd debate revised sixty years later. In: The Delaware Journal of Corporate Law. Vol. 16. No. 1. 1991. pp. 33-56

STIGLER, George J. The Theory of Economic Regulation. In: DAHL, Robert; SHAPIRO, Ian; CHEIBUB, José Antonio. The Democracy Sourcebook. Cambridge: The MIT Press, 2003. pp. 393-397.

STEPHEN, Frank H. Teoria econômica do direito. (trad. Neusa Vitale). São Paulo: Makron Books, 1999

STIGLITZ, Joseph E. Information and capital markets. NBER Working Paper No. 678. National Bureau of Economic Research. May, 1981

SWEENEY, Richard James; TOLLISON, Robert D.; WILLETT, Thomas D. Market failure, the common-pool problem, and ocean resource exploitation. In: The Journal of Law and Economics. Vol. 17. No. 1, apr./1974. pp. 179-192 
SZTAJN, Rachel; AGUIRRE, Basília. Mudanças institucionais. In: ZYLBERSZTAJN, Decio; SZTAJN, Rachel (Orgs.). Direito \& Economia: Análise Econômica do Direito e das Organizações. Rio de Janeiro: Elsevier, 2005. pp. 228243

SZTAJN, Rachel; ZYLBERSZTAJN; MUELLER, Bernardo. Economia dos Direitos de Propriedade. In: ZYLBERSZTAJN, Decio; SZTAJN, Rachel (Orgs.). Direito \& Economia: Análise Econômica do Direito e das Organizações. Rio de Janeiro: Elsevier, 2005. pp. 84-101

SZTAJN, Rachel. Law and Economics. In: ZYLBERSZTAJN, Decio; SZTAJN, Rachel (Orgs.). Direito \& Economia: Análise Econômica do Direito e das Organizações. Rio de Janeiro: Elsevier, 2005. pp. 74-83

SZTAJN, Rachel. Law and economics. In: Revista de Direito Mercantil, Industrial, Econômico e Financeiro. Ano XLIV, n. 137 jan./mar. 2005. São Paulo: Malheiros, 2005. pp. 227-232

TEPEDINO, Gustavo. Contornos constitucionais da propriedade privada. In: TEPEDINO, Gustavo. Temas de direito civil. Rio de Janeiro: Renovar, 1999. pp. 267-286

VIANNA, Mônica Peixoto. Habitação e modos de vida em vilas operárias. Monografia final. Dezembro, 2004

VILLELA, André. Dos "Anos Dourados" de JK à Crise Não Resolvida (1956-1963). In: GIAMBIAGI, Fábio; VILLELA, André; DE CASTRO, Lavínia Barros; HERMANN, Jennifer (Orgs.). Economia Brasileira Contemporânea: 1945-2010. Rio de Janeiro: Elsevier, 2011. pp. 25-48

WARDE JR., Walfrido Jorge. Os Poderes Manifestos no Âmbito da Empresa Societária e o Caso das Incorporações: a Necessária Superação do Debate Pragmático-Abstracionista. In: CASTRO, Rodrigo R. Monteiro de; MOURA 
AZEVEDO, Luís André N . de (Coord.). Poder de Controle e Outros Temas de Direito Societário e Mercado de Capitais. São Paulo: Quartier Latin, 2010. pp. 55 82

WEBER, Max. A ética protestante e o espírito do capitalismo. São Paulo: Editora Pioneira, 1985

WEINRIB, Ernest J. Deterrence and Corrective Justice. In: UCLA Law Review, 50, 2002. pp. $621-640$

WILLIAMSON, O. E. Por que Direito, Economia e Organizações? (trad. Decio Zylbersztajn). In: ZYLBERSZTAJN, Decio; SZTAJN, Rachel (Orgs.). Direito \& Economia: Análise Econômica do Direito e das Organizações. Rio de Janeiro: Elsevier, 2005. pp. 16-59

WILLIAMSON, O. E. Transaction Cost Economics Meets Posnerian Law and Economics. In: Journal of Institutional and Theoretical Economics. Vol. 149, No.1, 1993. pp. $73-87$

WITTMAN, Donald. Economic Foundations of Law and Organization. Cambridge University Press, 2006.

ZYLBERSZTAJN, Decio; SZTAJN, Rachel. Análise Econômica do Direito e das Organizações. In: ZYLBERSZTAJN, Decio; SZTAJN, Rachel (Orgs.). Direito \& Economia: Análise Econômica do Direito e das Organizações. Rio de Janeiro: Elsevier, 2005. pp. 1-15 